\title{
Management of Choroid Plexus Papillomas
}

K.Badache ${ }^{1 *}$, N.Habchi ${ }^{1}$, F /Z. Bendib ${ }^{1}$, F.Bouchnaki ${ }^{2}$, W. Abdelaoui ${ }^{2}$, N. Ioualalen ${ }^{2}$, M.Djaafer ${ }^{1}$

${ }^{1}$ Neurosurgery Department, MUSTAPHA PACHA University Hospital, Algiers, Algeria

${ }^{2}$ Neurosurgery Department ALI AIT IDIR Hospital Health Establishment, Algiers, Algeria

*Corresponding Author: K.Badache, Neurosurgery Department, MUSTAPHA PACHA University Hospital, Algiers, Algeria

Received date: December 10, 2021; Accepted date: December 27, 2021; Published date: January 03, 2021

Citation: K.Badache, N. Habchi, F /Z. Bendib, F.Bouchnaki, W. Abdelaoui et all. (2022). Management of Choroid Plexus Papillomas. J. Neuroscience and Neurological Surgery. 11(2); DOI:10.31579/2578-8868/225

Copyrights: () 2022 K.Badache, This is an open-access article distributed under the terms of The Creative Commons Attribution License, which permits unrestricted use, distribution, and reproduction in any medium, provided the original author and source are credited

\section{Abstract}

Introduction: Choroid plexus papillomas are rare neuroepithelial tumors found primarily in children. It represents less than $1 \%$ of all central nervous system tumors.

Materials and methods: A retrospective study including 14 patients with choroid plexus papilloma tumors were performed at the Neurosurgery Department in Ait IDDIR Health Hospital Establishment between January 2010 and December 2017. In each case, diagnosis was made clinically and confirmed radiologically and histo-pathologically. All patients were operated.

Results and discussion: The mean age was 26 years (ranged 3 months -48 years). In our department, we grouped together 14 cases of choroid plexus papilloma tumors. For mortality we had one case who died during surgery, survival rate for 04 years is $100 \%$.We had not recurrence during the study period.

All patients had intracranial hypertension (HIC) without neurological deficit and benefited from brain CT, MRI and an Angiography. The location of the tumor was: Lateral ventricle, Fourth ventricle, Third ventricle. All patients underwent surgical excision with or without ventriculo-peritoneal shunt.

Conclusion: Choroid plexus papillomas are rare neuroepithelial tumors, typically considered benign lesions, derived from the choroid plexus and appear like cauliflower.

Key words: choroid plexus papillomas; intraventricular tumor and surgical excision

\section{Introduction}

Choroid plexus papillomas (CPP) are a rare neuroepithelial tumors found primarily in children.

It represents less than $0.5-1 \%$ of all central nervous system tumors. They represent $2-5 \%$ of CNS tumors in children [1].

CPPs are benign tumors that grow slowly. They correspond to growths and appear as reddish, papillomatous tumors (compare to cauliflowers) [2]. 


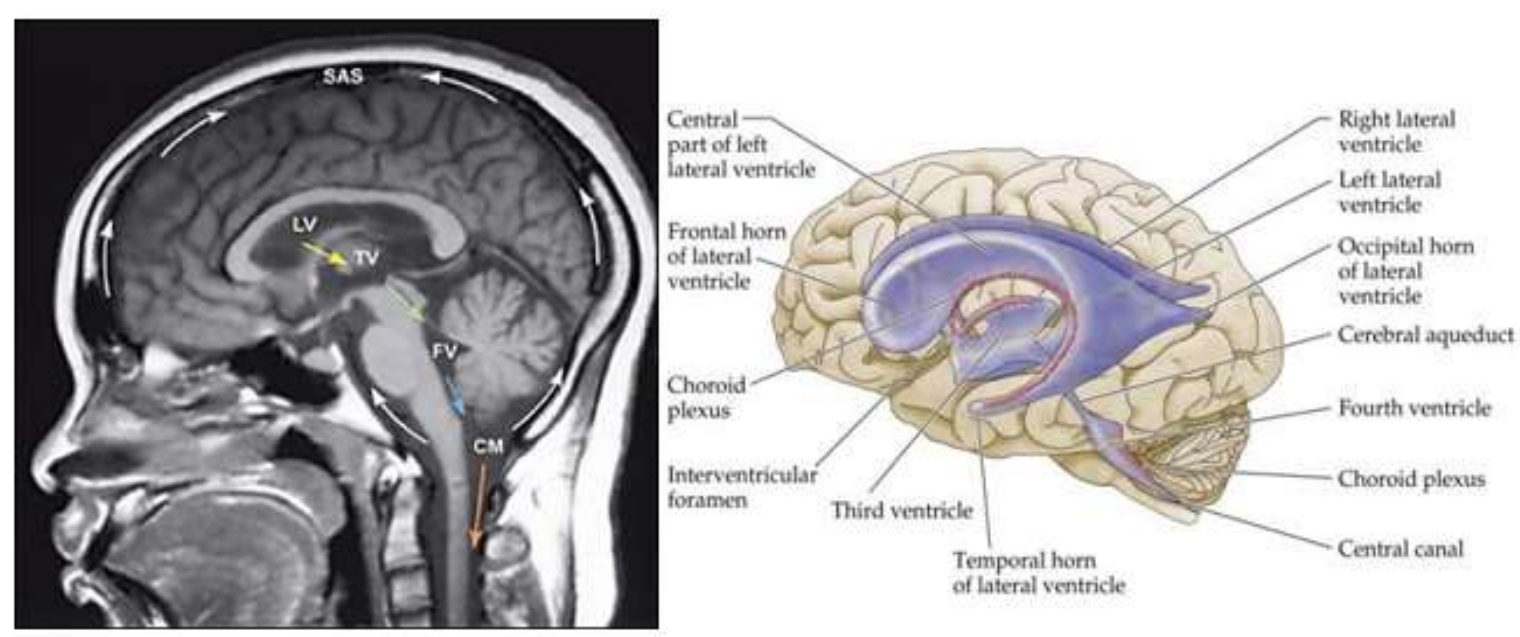

Ventricular system

\section{Materials and Methods}

Between January 2010 and December 2017, 14 cases of patients with Choroid Plexus tumors were treated, these are 9 male patients and 5 female (sex ratio: 1.8: 1) whose Age: 3 months - 48 years (average age: 26). We have 10 children / 4 adults.

Localization to the lateral ventricles was found in $58 \%$ ( 8 cases), fourth ventricle at $21 \%$ ( 3 cases), at the third ventricle in $14 \%$ ( 2 cases) and in the cerebellar ponto angle $7 \%$ (1 case).

Clinical manifestations are represented by an intracranial hypertension syndrome in $80 \%$ of cases (headache, nausea, vomiting), It may be a Macrocrania (tense fontanelle) $21 \%$ of cases, signs of cerebral focalizations are observed in only $7 \%$ of cases (signs of deficiency), Cerebellar Ataxia including $14 \%$ of cases, Deafness in $7 \%$ of cases, Intraventricular haemorrhage $7 \%$ of cases and cries of epilepsy in $14 \%$ of cases.

Complementary examinations are based on CT event, all of our cases benefited from this rapid examination allowing a definite diagnosis (figures 1, 2 and 3). MRI allowed us to better appreciate the tumor morphology and its extension through the ventricle (figure 4).
Angiography identifies the vascularization (a process highly vascularized by the choroidal arteries), Echo trans fontanel was performed for children under 10 months. Figure 1, 2 and 3

Surgical excision was performed in all cases allowing the tumor to be removed iin total in $65 \%$, subtotal $35 \%$ of cases. Ventriculoperitoneal bypass by pre and post operative valve in $68 \%$.

The operative consequences were presented by a transient neurological motor deficit $2 / 3$ cases which is due to a cortectomy (intraventricular $\mathrm{PCP})$, an intraventricular hematoma in 1 case, an aphasia in 1 case, a persistent Hydrocephaly in 2 cases, an infection and fistula of the CSFin 4 cases, Cognitive impairment in 1 case, Ascites in 1 case due to the ventriculo-peritoneal derivation and in whom subsequently a ventriculoatrial derivation was performed.

The survival time is 36 months, we observed no recurrence in the case of total excitation during the study period and in the event of subtotal excitation the cerebral MRI was performed every 6 , the recurrence is $14 \%$ of cases. Mortality in one per-operative case, Survival for 5 years is $100 \%$

NO RECURRENCE in cases of total EXERSE during the study period.

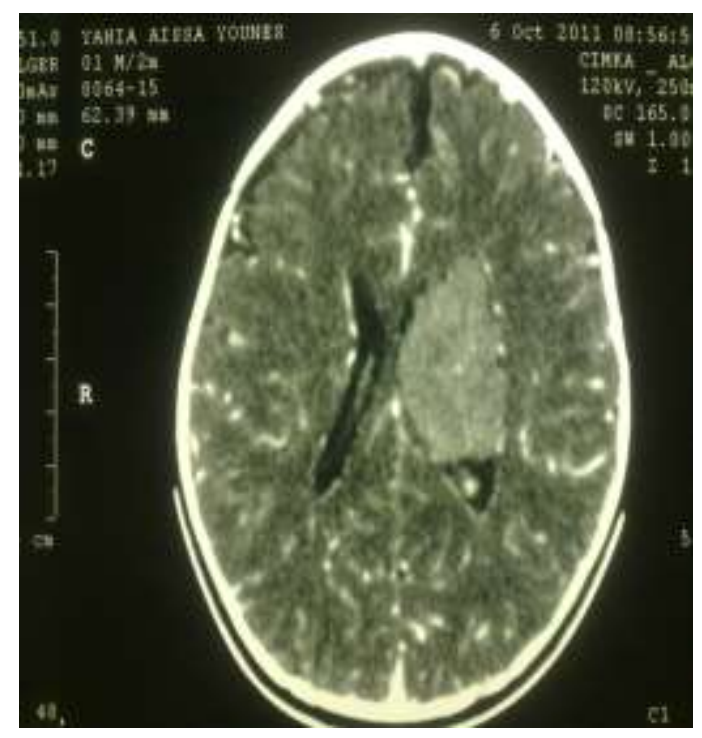

Figure 1: Brain CT of a Child aged 6 CPP located in the left lateral ventricle. 


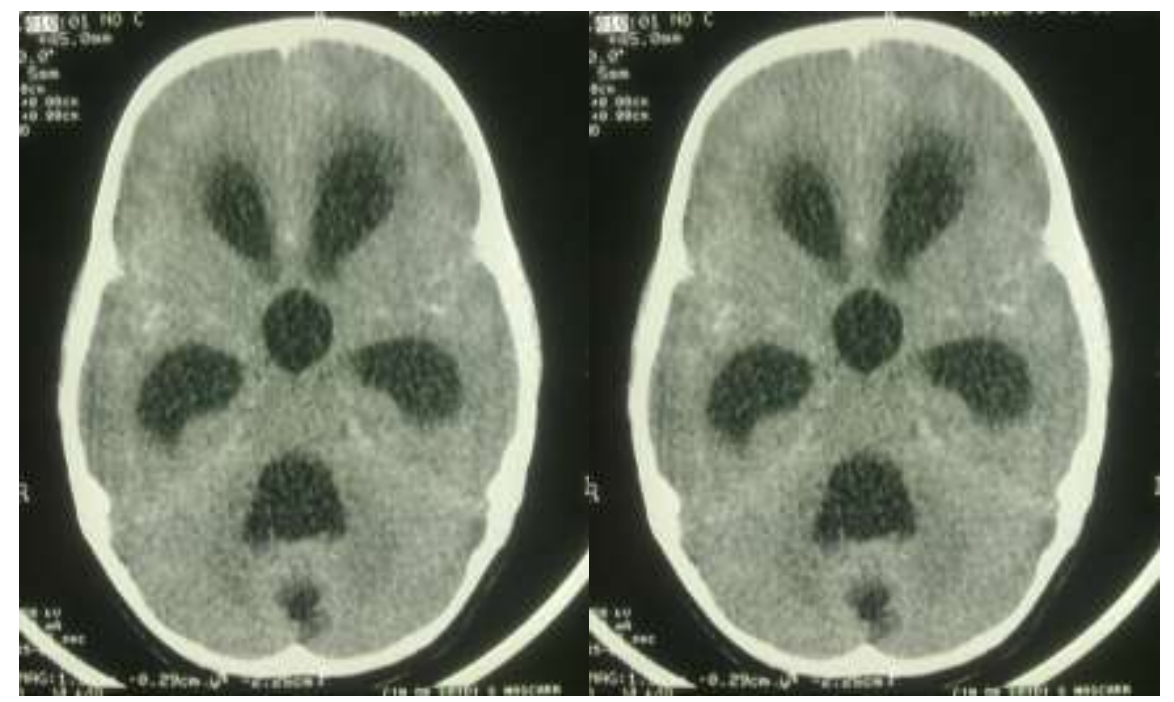

Figure 2: Brain CT CPP of Ventricular careffour with ventricular dilation

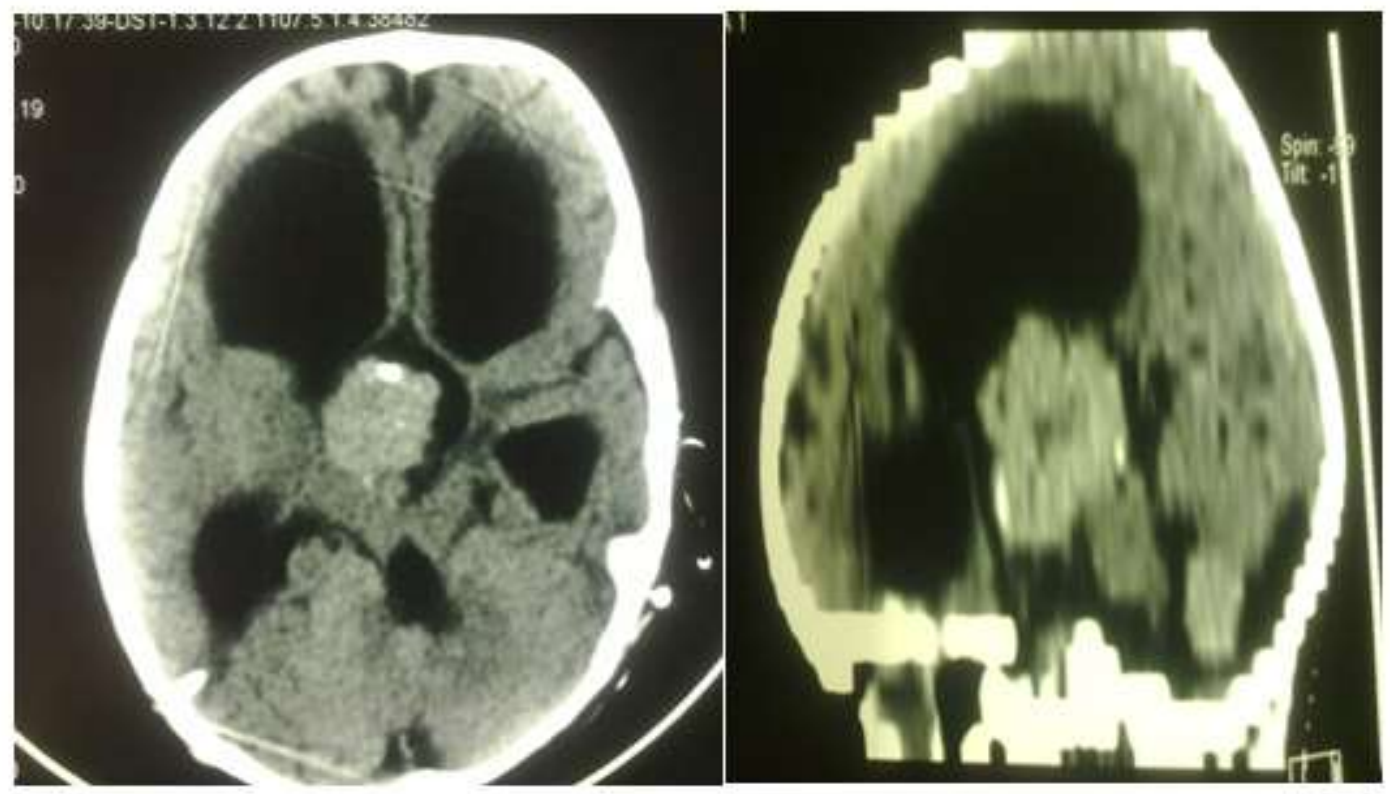

Figure 3: Brain CT shows that the CPP is located at the level of the 3rd Ventricle (axial and sagittal slices)

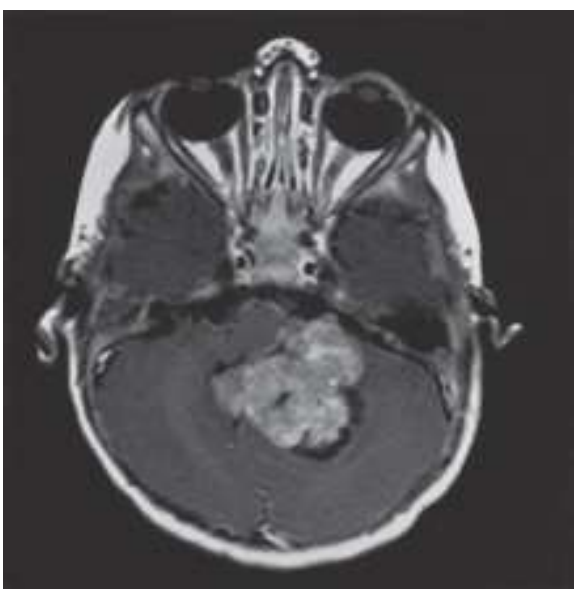




\section{Discussion}

Choroid plexus papillomas is a rare, benign, intraventricular tumor, very common in children very rare in adults, $2-5 \%$ of pediatric brain tumors (1and 2). It is considered as rare, benign, intraventricular tumor.The lateral ventricles, readily the ventricular junction, rarely the 3rd ventricle and the ponto-cerebellar angle. The localization at the level of the 4th ventricle is especially encountered in adults [4].

In our series these tumors are located in the regions where the choroid plexuses are usually located, i.e. the lateral ventricles (50\%), the 3rd ventricle (5\%) and the 4th ventricle (40\%). More rarely, they develop at the level of the pontocerebellar angle.

The first case was discovered by chance during an autopsy of a child who died of broncho-pneumopathy in 1833 by Guèrard, the first surgical excision was performed by Dandy in 1927, in 1933 Masson succeeded in performing a surgical excision with success. .

The increase in intracranial pressure is the most frequent symptom most often due to obstruction of the CSF outflow pathways, disorder of CSF resorption and CSF hypersecretion by sustained tumor hyperproduction by several authors (Milhoart demonstrates that hyperproduction before the operation and markedly decrease after surgery); some Hydrocephalus which persists after surgery (1 case in our series).

Cerebral meningeal hemorrhage from the tumor (highly vascularized tumor). Hence the importance of a cerebral angiography in our series allows the identification of vascularization (a process highly vascularized by the choroidal arteries) $21 \%$ of cases.

Computed tomography (CT) and R.M.N have helped a lot in the diagnosis and in the treatment strategy; on CT Tumor aspect:, intraventricular process, intensely enhanced hyperdense, NMR: very important modality

Unfortunately, in our $71 \%$ of the cases, the form of a clearly contoured polylobed process with intraventricular extension (lateral ventricle, ventricular hub, fourth ventricle) was not available in all cases in our series.

Treatment is surgical: all patients have undergone surgical excision with or without DVP, surgical excision should be as complete as possible.

Surgical life depends on tumor location, the trans-frontal-Trans-cortical route has been useful for third ventricular lesions.

According to several authors (H. Yettou, JCMarchall) the frontal Trans cortical route is facilitated by the intra ventricular approach, the anatomical landmarks of the third ventricle, the interventricular foramen, the choroid plexus, thalamo -striated vein the section of this will allow the direct approach by the interthalamo-trigonal approach. the temporooccipital pathway is indicated for Tumors which sit at the level of the ventricular crossroads through the T1 - T2 groove if the tumors sit at the Parieto-occipital level the surgical approach will be through P1 -P2, for tumors of the fourth ventricle the approach is the sub-occipital median way and if the tumors sit at the level of the ponto-cerebellar angle the approach is under the lateral occipital retroauricular, the drainage of hydrocephalus is done either by an external drainage at the time of the intervention (intraoperative) or by internal drainage through ventriculoperitoneal drainage before surgical excision.

The anatomo-pathological study of choroid plexus tumors shows macroscopically a Cauliflower appearance, a very vascular globular papillary mass of reddish color sometimes pinkish gray of variable size with an insertion on the choroid plexus by cons microscopically the histological appearance of the choroid plexus, an epithelium made up of a single layer of cubic or columnar cells with a basophilic nucleus with numerous villi. Davis described villous hypertrophy as gross hypertrophy.

-Selective embolization will be helpful in reducing the degree of vascularity and may facilitate total resection [3].

-The use of tractography, fMRI, and neuronavigation may minimize the risk of postoperative neurologic deficits when the tumor is near / in meaningful areas of the brain [4].

\section{Conclusion}

Choroid plexus papillomas are intraventricular lesions, histologically benign but highly vascular. The choice of surgical approach differs depending on the location of the lesion.

Total resection offers good prognosis.Adjuvant therapies are not necessary. Total surgical exercise should be the goal in each case.

\section{References}

1. B.Kammoun, F.Kolsi, Y. Gdoura, O.Kammoun, F.Jarraya, R.Kallel, H.Ben Ali, M.Z.Boudawara : les tumeurs du plexus choroïde tumors of choroid plexus

2. Berger C, Thiesse P, Lellouch-Tubiana A, Kalifa C, Pierre-Kahn A, Bouffet E. Choroid plexus carcinomas in childhood: clinical features and prognostic factors. Neurosurgery. 1998 Mar;42(3):470-475.

3. Wrede B, Liu P, Ater J, Wolff JE: Second surgery and the prognosis of choroid plexus carcinoma--results of a meta-analysis of individual cases.Anticancer Res. 2005 Nov-Dec;25(6C):44294433.

4. S.De La Rosa ,M.Beltramone,C.Bouvier,V.Lubrano,P.Roche Papillomes des plexus choroïde impliquant la citerne cérébello-médullaire : formes topographiques et implications chirurgicales,

5. M.Vinchon,M.Baroncini, P.Leblond : Tumeurs du ventricule latéral de l'enfant : particularités et spécificitésTumors of the lateral ventricle in child: Characteristics and specificities,
This work is licensed under Creative Commons Attribution 4.0 License
To Submit Your Article Click Here: Submit Manuscript

DOI: $10.31579 / 2578-8868 / 225$
Ready to submit your research? Choose Auctores and benefit from:

$>$ fast, convenient online submission

$>$ rigorous peer review by experienced research in your field

$>$ rapid publication on acceptance

$>$ authors retain copyrights

$>$ unique DOI for all articles

$>$ immediate, unrestricted online access

At Auctores, research is always in progress.

Learn more https://auctoresonline.org/journals/neuroscience-and-neurologicalsurgery 